\title{
Surgery of the rheumatoid elbow
}

\author{
W A Souter
}

The functions of the elbow are threefold:

(a) as a component joint of the lever arm which positions the hand; $(b)$ as a fulcrum for the forearm lever; and $(c)$ as a weightbearing joint. In the very disabled patient this may become of vital importance during such activities as rising from a chair or walking with crutches.

To fulfil these functions the elbow must be free from pain, mobile, and stable. As a result of rheumatoid arthritis all three of these requirements may be lacking, so that elbow function, especially in the later stages of disease, can become greatly impaired.

\section{Incidence of elbow disease in rheumatoid arthritis}

Laine and Vainio reported unilateral disease in $21 \%$ of 191 patients with definite or classical rheumatoid arthritis, with no less than $45 \%$ affected in both elbows. ${ }^{1}$ Freyberg found clinical and radiological evidence of elbow disease in $38 \%$ of patients with a history of rheumatoid arthritis ranging from five to 25 years. ${ }^{2}$ Porter, Richardson, and Vainio reviewing a hospital population of 225 patients found that only $28 \%$ had no evidence at all of elbow pathology, while as many as $25 \%$ had severe disease. ${ }^{3}$ Gschwend found evidence of elbow disease in $53 \%$ of a large personal series of 300 patients, with an average duration of disease of 10 years. $^{4}$

\section{Pathology of rheumatoid elbow disease}

Rheumatoid arthritis can manifest itself in a variety of ways in the elbow joint, including nodules and bursae, synovitis, progressive joint destruction, antecubital cysts, and ulnar or, rarely, posterior interosseous nerve palsy. The antecubital cysts usually occur during acute episodes of extremely hyperplastic synovitis due to herniation of synovium through the relatively weak anterior capsule of the joint. The nerve palsies also arise from synovial herniation. In the case of the ulnar nerve, pressure may arise from protrusion of synovium under the transverse section of the medial collateral ligament bridging the gap between the posterior and anterior bands of that structure. The presence of such a synovial cyst in the very confined tunnel formed by the posterior surface of the medial epicondyle anteriorly and the arcuate ligament posteriorly can readily give rise to ulnar neuropathy. Synovium in the anterolateral compartment of the elbow normally forms a blind pocket lining the interval between the annular ligament and the head of the radius.
Where there is severe proliferative synovitis with marked tension within the joint this pocket can be pushed distally from under the margin of the annular ligament as a synovial cyst dissecting into the tissue of the forearm. Any such protrusion is likely to displace the posterior interosseous nerve against the sharp tendinous margins of the origin of the extensor carpi radialis brevis and the superficial humeral lamina of the supinator muscle (the ligament of Frohse). Paralysis of the posterior interosseous nerve will result in total loss of extension of the fingers and, though a rare occurrence, must be entertained in the differential diagnosis of massive extensor tendon rupture.

By far the most important aspect of rheumatoid disease in the elbow is the steady erosion of the joint surfaces. The radiological deterioration can usefully be graded into five stages:

Stage 1 -characterised by soft tissue swelling and perhaps some osteoporosis.

Stage 2-where there is only very slight narrowing of the joint space and some marginal erosion.

Stage 3-where the joint space is becoming definitely narrowed (fig 1).

Stage 4-where the integrity of the subchondral plates is breached by deep erosions (fig 1).

Stage 5-characterised by total joint destruction with complete loss of the normal articular contours (fig 1).

Hastings and Kwok examined 140 radiographs of 80 elbows in $\mathbf{4 0}$ patients in an effort to study the natural history of the progression of rheumatoid erosion. ${ }^{5}$ In phase 1 of this process they considered that although there might be some early loss of cartilage space, the main problem was one of synovitis and periarticular osteoporosis. In phase 2 there was significant loss of cartilage in both the humeroulnar and radiocapitellar joints, and this could also be accompanied by marginal erosions. In phase 3 the main brunt of the destruction seemed to fall on the humeroulnar joint, while little progression might take place in the radiocapitellar joint. What did occur in the latter, however, was an anterior subluxation of the radial head relative to the capitellum. In this position it appeared to become a mechanical block to flexion and extension once there was erosive change in the trochlea. Hastings and Kwok accordingly suggested that although conservative medical treatment might be appropriate to phase 1 and surgical synovectomy to phase 2 , in phase 3 excision of the radial head was imperative if optimal function was to be restored to the joint. In the final phase 4 , there was extensive
Princess Margaret Rose Orthopaedic Hospital, Edinburgh

W A Souter 
Figure 1 Radiographs of elbow showing, from left to right, stages 3, 4, and 5 of rheumatoid erosion.

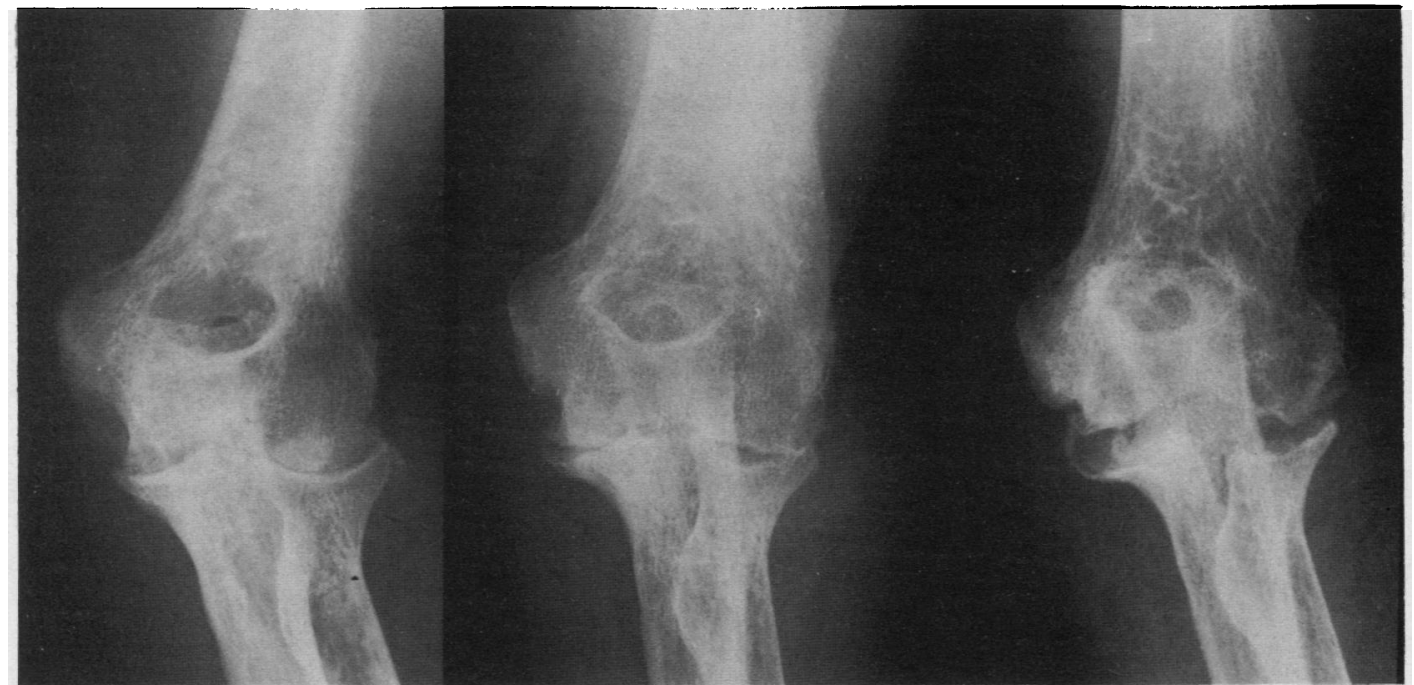

destruction of the humeroulnar joint so that the trochlear notch of the olecranon migrated proximally into the now markedly deficient trochlea of the humerus. Moreover, they pointed out that this proximal migration was responsible for the appearance on lateral radiographs of the capitellum seeming to overlie the ulna so that the inexperienced observer might be led to assume that the film had been incorrectly taken at an oblique angle. Hastings and Kwok pointed out that at this phase of joint destruction the head of the radius may be acting as a major stabilising force against the front of the capitellum so that in the event of surgical treatment being attempted merely by means of synovectomy, joint debridement, and excision of the head of the radius, the instability of the elbow may be markedly increased. They therefore recommended that at this phase of the disease total joint replacement was indicated. I agree with this and would further advocate that joint replacement should not be too long delayed because if phase 4 changes are allowed to persist untreated the impingement of the head of the radius on the front of the capitellum can produce such erosion and flattening of the latter that the bone available for anchorage of an implant can become very seriously impaired (fig 2).

At any stage of the natural history of the disease the rheumatoid process may of course go into remission and under these circumstances a form of pathological healing can occur in which the poorly defined, fluffy outline of the actively eroding and perforated subchondral plate may once more become clearly delineated as smooth sclerotic surfaces, which can apparently function very adequately for many years (fig 3 ). Moreover, it seems likely that this may be one of the mechanisms whereby a successful synovectomy of the elbow achieves its beneficial result (fig 4).

It is also of interest that in passing from stage
Figure 2 Radiograph showing severe capitellar erosion from impingement of residual radial head in association with severe erosion and early proximal migration of ulnohumeral joint.

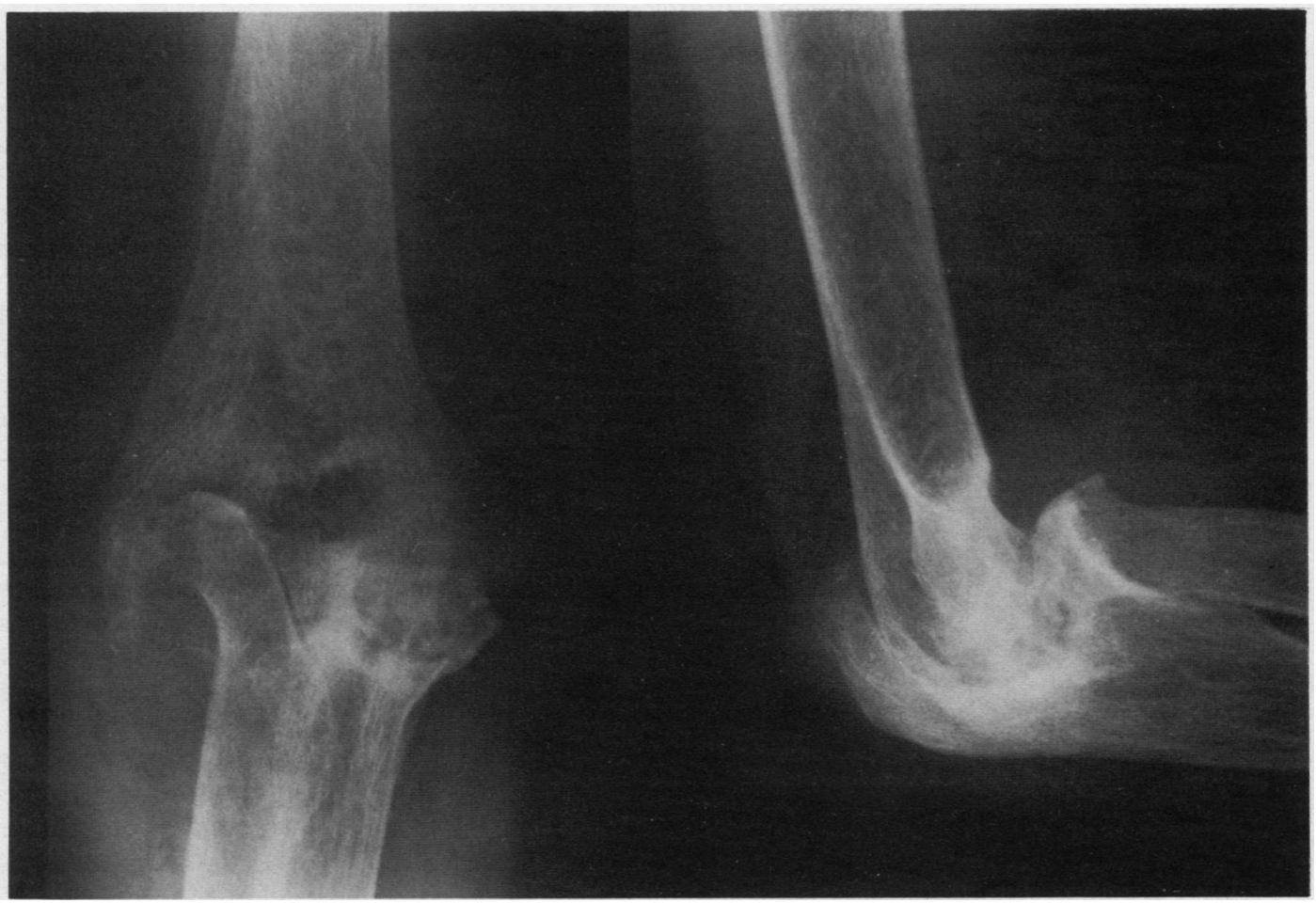



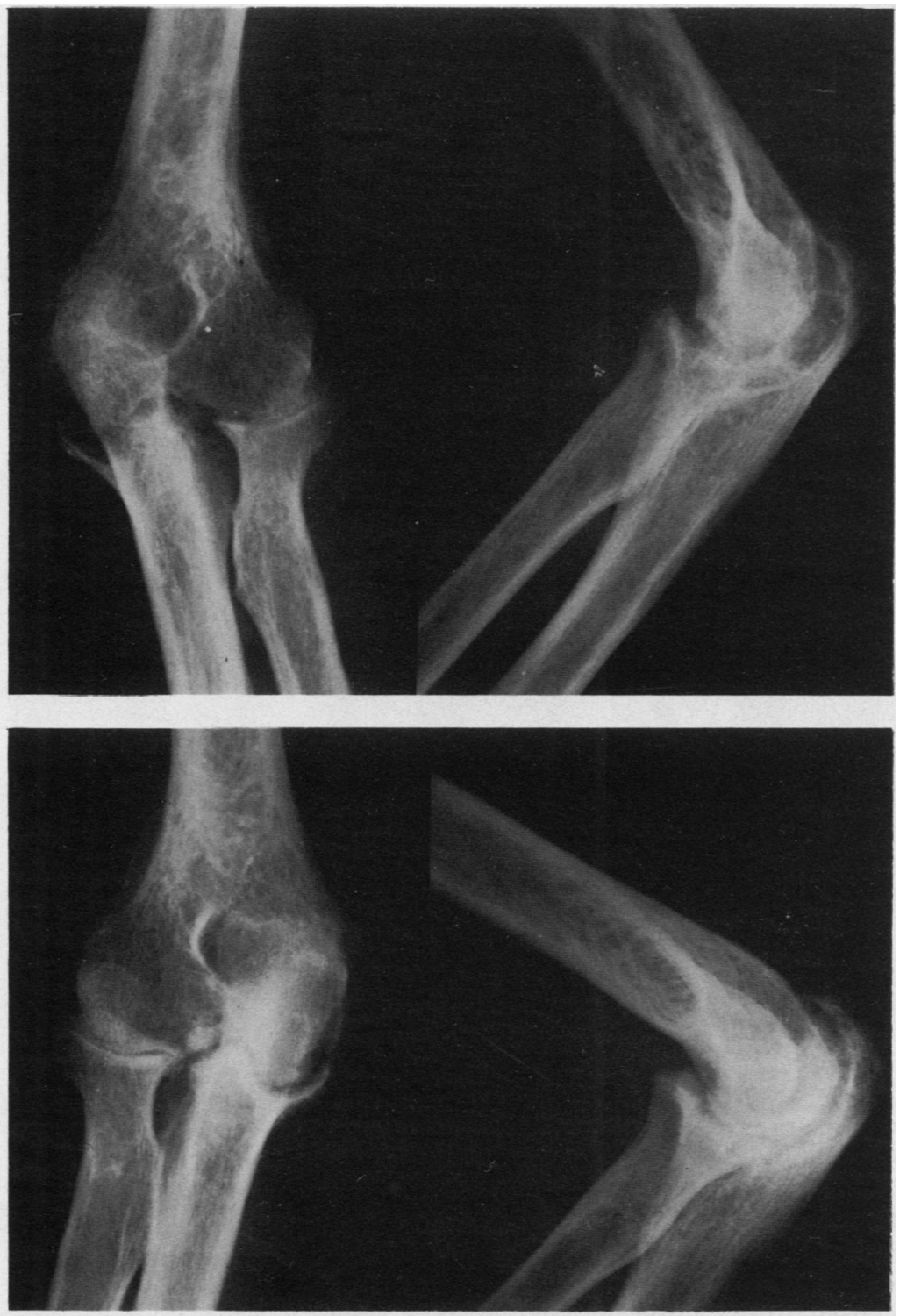

Figure 3 Upper radiographs of left elbow show appearances typical of active erosion with osteoporosis and poor definition of subchondral plates. The lower radiographs show the right osteoporosis and poor definition of subchondral plates. The lower radiographs show the right
elbow in the same patient. This joint had been the seat of similar active disease some years previously, but had subsequently become completely free from symptoms. The radiographs suggest healing with reconstitution of clearly defined, if somewhat sclerotic, subchondral plates.
4 to stage 5 of radiological erosion the elbow may become relatively free from pain, the patient as it were achieving his or her own excision arthroplasty. This, however, is much too indeterminate a process to be relied on as a potential route of management for the rheumatoid elbow, especially as there is no guarantee that the erosion will become arrested at a stage when the joint still retains a reasonably acceptable degree of stability. Instead, total trochlear destruction may gradually occur with migration of the olecranon proximally into the residual fork formed by the supracondylar ridges of the humerus. The main stress of such an articulation, however, is likely to fall on the medial ridge owing to the latter's horizontal obliquity, as compared with the essentially vertical alignment of the lateral ridge. Because the compression forces across the elbow can amount to as much as half the body weight, even during such simple activities of daily living as dressing and eating, and to three times the body weight in such activities as walking with crutches, ${ }^{6}$ there exists a major risk of stress fracture of the medial ridge. Indeed this does occur all too often in these extremely eroded joints so that complete medial dislocation of the elbow must inevitably follow, the joint becoming totally flail (fig 5). Appropriate surgical intervention at stages 3,4 , or early 5 of the disease should completely avert this catastrophe.

Clinical presentation of the rheumatoid elbow By far the most important and commanding symptom is likely to be pain. In the early stages of the disease this may be due to acute synovitis, giving rise to considerable swelling and tenseness of the joint. It is remarkable how seldom the patients themselves seem to be aware of elbow swelling, even when this is considerable. Later in the disease much more severe and intractable pain is likely to occur in association with bone erosion. Severe pain can result in major disability as the patient may be forced to avoid using the arm as much as possible in order to keep the discomfort within bearable limits. As a result it is not at all uncommon to find the natural dominance reversed so that a normally right handed person may become largely left handed.
Figure 4 The left hand radiograph shows an actively erosive picture in an elbow subsequently treated by synovectomy. The middle and right hand radiographs show the increased bone density and the reconstitution of the subchondral plates, which characterise a successful and durable postoperative result.

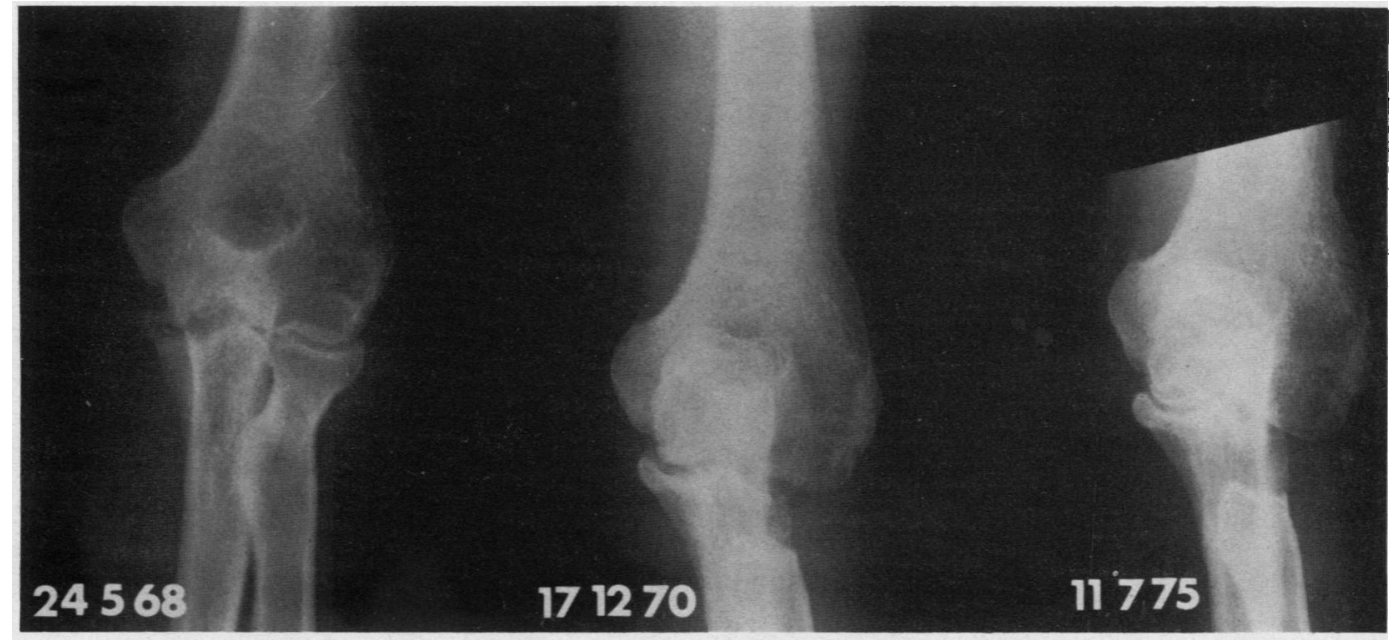


Figure 5 Radiographs showing progressive deterioration within stage 5 of rheumatoid erosion.

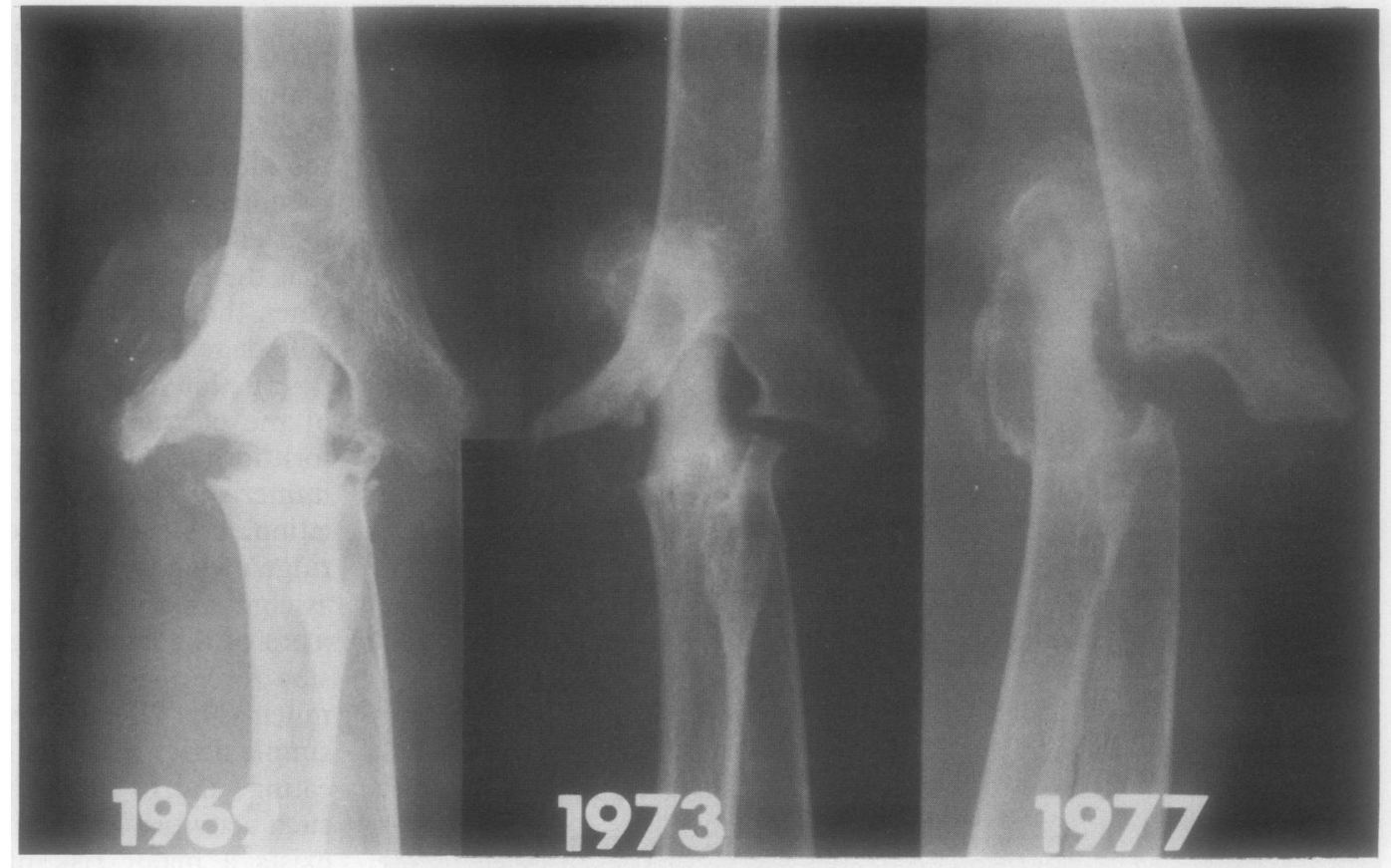

As some degree of loss of elbow extension is commonly found in patients who appear to be unaware of any elbow problem it seems likely that the elbow may be significantly affected quite early in the disease without much in the way of discomfort or loss of function. Major loss of movement and function seem to be manifestations of late disease. Thus all too often by the time the patient is seen at the surgical clinic the opportunity for minor conservative surgery has passed and radical reconstruction of the joint is likely to be necessary. This problem of late presentation of elbow disease was noted by Wilson, Arden, and Ansell. ${ }^{7}$ In a series of 57 elbow synovectomies undertaken in $\mathbf{4 8}$ patients nearly all the elbows showed such severe radiological changes that there seemed little doubt that they had been the seat of disease for a long time. Certainly in systemic disease only $15 \%$ of the patients had had rheumatoid disease for less than five years. Despite this, $53 \%$ of the patients claimed that their elbow symptoms had been present for under two years, and only $15 \%$ reported early symptoms. It was accordingly concluded that patients tended to ignore their elbow symptoms because of the more commanding disability which was likely to arise from disease of other joints, especially in the legs and in the hands.

Morrey et al showed that a functional arc from 30 to $130^{\circ}$ would allow the execution of virtually all activities of daily living, while the vast majority could be accomplished provided that the elbow retained a range from 60 to $120^{\circ} .^{8}$ Obviously the overall disability will also be dependent on the state of the other arm joints, particularly the shoulder elevation and rotation. If the minimum vital arc of movement to ensure adequate elbow function is $60-120^{\circ}$ it is obviously important that this should remain a realistic goal of any reconstructive surgery. There should be no problem with achieving $120^{\circ}$ of flexion because even in an elbow showing very major loss of flexion total joint replacement is likely to be followed by very significant gains. The situation for extension is very different, however. Here the experience of most workers has been that the range after surgery is likely to be little improved. It is therefore of great importance that patients are not allowed to develop flexion deformities greater than $60^{\circ}$ as this may render it very difficult, if not impossible, for the surgeon and physiotherapist to restore a really functional range of movement postoperatively.

The final clinical problem for the patient may be the development of instability, which is only likely to occur after there has been extremely severe bone destruction. With good combined medicosurgical supervision this situation should not be allowed to develop.

\section{Indications for operation}

When the foregoing account of the pathology, radiological deterioration, natural history, and clinical presentation are taken into account the indications for operation in early or late disease can be summarised as follows:

\section{IN EARLY DISEASE}

The persistence of painful synovitis of the elbow despite good medical treatment, including the use of disease modifying drugs and intraarticular steroids over nine to 12 months, especially in the presence of stage 2 or early stage 3 radiological changes, should be regarded as an indication for synovectomy, coupled as seems appropriate with excision of the head of the radius. The occurrence of sizable intraosseous cysts or geodes at the olecranon-coronoid required. If neglected these lesions can result in spontaneous pathological fracture with a major risk of non-union and the subsequent need for very extensive linked joint replacement. By immediate surgical intervention with radical synovectomy of the joint and clearance of the pannus from the cyst, which should then be junction is an indication that surgery is urgently 
Figure 6 (A) Radiographs showing pathological fracture through a rheumatoid cyst at the olecranon-coronoid junction. (B) Radiograph showing gross stage 5 rheumatoid erosion with enormous cystic destruction of the whole lateral condyle of the humerus.
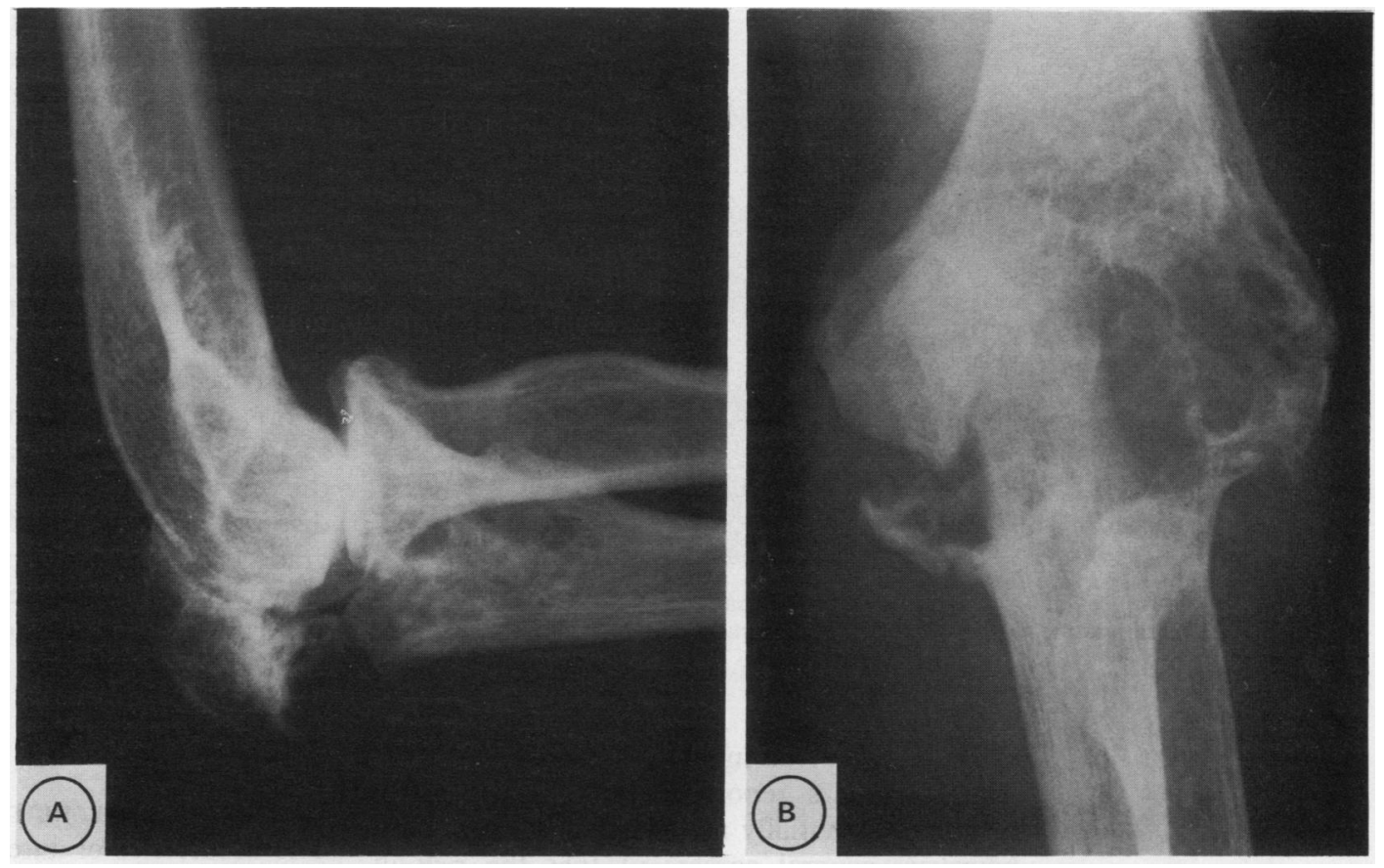

packed with cancellous bone, these catastrophes may be avoided.

\section{IN LATE DISEASE}

Total replacement arthroplasty should be very seriously considered in the presence of:

1 Severe intractable pain in association with severe grade 3,4 or 5 erosions.

2 Major cysts at the olecranon-coronoid junction, in association with severe grade 3-5 erosions. In these circumstances surgery is urgently required (fig $6 \mathrm{~A}$ ).

3 Progressive loss of extension beyond $60^{\circ}$.

4 Instability which indicates very severe bone destruction and endangered ligamentous stability.

5 Progressive radiological deterioration within grade 4 . If such changes are obvious surgery should not be delayed until the patient has deteriorated into grade 5 as the bone stock available for fixation of any implant will then be very much poorer and a modification in the operative technique may become necessary. Thus major cystic change within the humerus, especially in the area of the capitellum (fig 6B), must be monitored very carefully with serial radiographs because, if such pathology is allowed to go unchecked, sudden disastrous collapse of the surrounding shell of bone may occur, the disease passing rapidly from grade 4 to advanced grade 5. Moreover, if this collapse has not occurred spontaneously, at surgery the destruction of bone may be found to be so great that the outer shell of the humeral condyles disintegrates, thus rendering the fitting and fixation of standard prosthetic components extremely difficult or impossible.

\section{Surgical management}

To deal with the full spectrum of rheumatoid disease the surgeon has at his disposal a considerable armamentarium: $(a)$ excision of nodules and bursae; (b) synovectomy; (c) excision of synovial cysts; (d) excision of the radial head; $(e)$ anatomical or excision arthroplasty; $(f)$ total joint replacement; $(g)$ arthrodesis; $(h)$ decompression of ulnar or posterior interosseous nerves, or both.

\section{EXCISION OF NODULES AND BURSAE}

Rheumatoid nodules over the posterior border of the olecranon or ulna are such an inherent part of rheumatoid disease that it is doubtful if there is any point in their routine removal. Where, however, they become large and unsightly, and especially if they are affecting the skin with a threat of ulceration (fig 7), their removal is certainly justified if for no other reason than to remove a potential source of infection should surgery in the elbow joint itself be required at a later date. A similar philosophy of management is applicable to olecranon bursae. If surgery is undertaken patients should always be warned of the strong possibility of recurrence. In the case of bursae it must also be remembered that some of these may be in communication with the synovial cavity of the elbow. Where this is the case any lasting result will only be achieved when synovectomy of the joint itself is undertaken.

\section{SYNOVECTOMY}

The indications for synovectomy have already been discussed. The operation, usually done in conjunction with excision of the head of the radius, first came to prominence with the reports of Laine and Vainio ${ }^{1}$ and Mori. ${ }^{9}$ Several other major reports followed from a number of centres during the next five years. ${ }^{3} 710-13$

In the main these reports were fairly enthusiastic, pain being abolished in $80-90 \%$ of the cases. More varied opinions were expressed about restoration of movement, some authors finding that significant gains in flexion and 


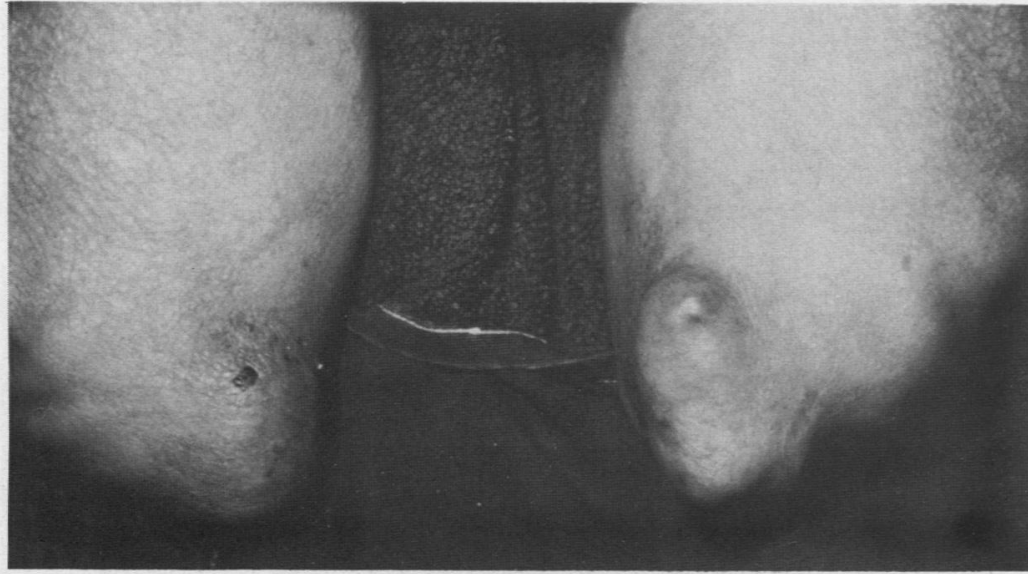

Figure 7 Rheumatoid nodules with early invasion of the skin. Such lesions are likely to harbour infection and constitute a major risk for any subsequent attempt at total joint replacement.
Figure 8 Radiographs showing progressive rheumatoid erosion from stage 3 to advanced stage 4 despite an initially clinically successful surgical synovectomy. extension occurred in $30-55 \%$ of cases, ${ }^{7} 101213$ whereas others reported either very variable results or essentially no change. ${ }^{3} 11$ There was, however, general agreement that the risk of sustaining a significant loss of movement was only of the order of $10-15 \%$.

Recurrence of synovitis was averred by most authors to be uncommon $(0-12 \cdot 5 \%),{ }^{1} 79-13$ though Porter et al in their series of 154 elbows did suggest that the incidence of recurrent synovitis might be as high as $20 \% .^{3}$ Warnings were also sounded by Porter $e t a l^{3}$ and by Brattstrom and Alkhudairy ${ }^{12}$ that synovectomy did not seem to arrest the radiological deterioration. More recent long term follow ups have confirmed that the results of elbow synovectomy are not materially different from those of synovectomy of other joints, and indeed there is no logical reason for expecting that the situation should be otherwise. Summers, Webley, and Taylor in reviewing a series of 65 elbows in 50 patients with a mean follow up of five years found that only $54 \%$ of the elbows at review had little or no pain, though $84 \%$ had been free from pain six months after surgery. ${ }^{14}$ Moreover, active synovitis was found in 39\% of elbows, and $36 \%$ had been given one or more intra- articular steroid injections. These results very much mirrored my own observations in a review of 40 elbow synovectomies with a mean follow up of five years. ${ }^{15}$ Although the results for pain relief and absence of synovial swelling were excellent at one year after surgery, there had been considerable deterioration in the quality of results by the time of the final review, $30 \%$ of the elbows showing a recurrence of significant pain and $25 \%$ moderate to severe synovial hyperplasia (fig 8).

It is not my intention to belittle synovectomy as a line of surgical treatment. It can be one of the most powerful weapons at the surgeon's disposal in dealing with rheumatoid disease of grade 1, 2, and early grade 3 severity. Nevertheless, it must be clearly realised that the operation, at least in a proportion of cases, will merely buy time before further definitive surgery is required.

\section{EXCISION OF ANTECUBITAL CYSTS}

The occurrence of antecubital synovial cysts is comparatively rare, and certainly in no way rivals the prevalence of this type of pathology in association with the rheumatoid knee. As the cysts originate from undue pressure within the parent elbow joint synovectomy of the latter is likely to result in spontaneous resolution of the cystic lesion. Where they persist despite synovectomy of the elbow, their direct removal through an anterior approach in the cubital fossa is a simple procedure.

\section{DECOMPRESSION OF NERVES}

The pathology responsible for the occurrence of ulnar and posterior interosseous nerve palsies has already been described. Decompression of the ulnar nerve by division of the arcuate ligament may be sufficient to relieve the symptoms. Where this does not prove to be the case, transposition of the nerve deep to the flexor origin may be necessary. In practice even this cannot always be guaranteed to provide relief from the symptoms, and it seems likely 
that ulnar nerve palsy in some rheumatoid patients may be of vasculitic origin.

Posterior interosseous nerve palsy due to rheumatoid disease was originally described by Marmor, Lawrence, and Dubois, who reported a single case in which temporary improvement was achieved with steroid injection, but relapse later occurred. ${ }^{16}$ Synovectomy and excision of the head of the radius resulted in permanent cure. Millender, Nalebuff, and Holdsworth reported a further three cases. ${ }^{17}$ Of these, one recovered following steroid injection, one after synovectomy, and the third, with very longstanding paralysis, was treated by flexor digitorum superficialis tendon transfer.

\section{ANATOMICAL OR EXCISION ARTHROPLASTY}

Although this procedure can sometimes yield remarkably satisfactory results in post-traumatic pathology in young patients with good musculature, the results in rheumatoid patients tend to be much less satisfactory, though even here occasional good results can be encountered. The deficiencies of excision arthroplasty in rheumatoid patients are twofold. Firstly, the patients

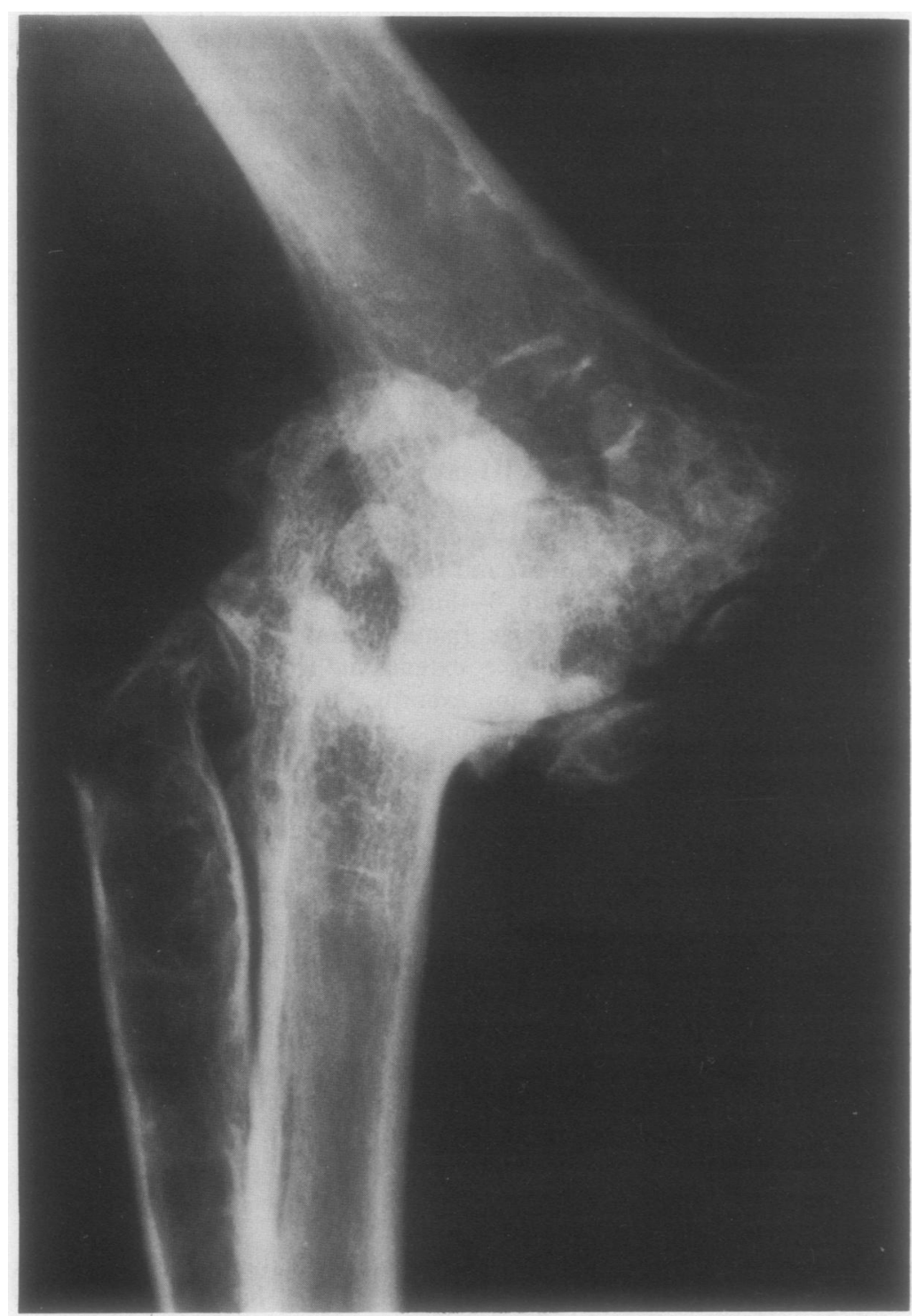

Figure 9 Radiographs showing the gross bone distortion and joint subluxation that can follow excision arthroplasty. commonly lack sufficient muscle power to stabilise the pseudarthrosis, and, secondly, they seem to be prone to progressive instability from further bone resorption. These problems were defined by Hurri, Pulkki, and Vainio as far back as $1964,{ }^{18}$ yet many centres have continued to make use of this procedure right up to the present time in the misguided belief that the procedure is safer than total elbow replacement and that if it does fail in the long term, total joint replacement can then be invoked as a last resort. It cannot be too strongly stressed that as a result of the advances which have been made in elbow arthroplasty over the past decade such a philosophy is no longer tenable and may have disastrous results, reducing the possibility of ever achieving an ideal, satisfactory, and durable total joint replacement. The degree of bone destruction that can occur after an excision arthroplasty (fig 9) may be such as to render the fitting of a surface or condylar replacement quite impossible so that a linked implant must be used, with all the increased risks that this entails for ultimate loosening of the prosthesis. In view of this I would contend that excision arthroplasty of the adult rheumatoid elbow, except as a salvage procedure for an infected total joint replacement, must be regarded as obsolete.

\section{ARTHRODESIS}

There is no position of the elbow which is ideal for the full spectrum of its activities, and thus arthrodesis can never be more than a second rate solution to the problem of a severely eroded joint. Moreover, it is not without significance that patients with juvenile chronic arthritis, with bony ankylosis of the elbow, often find this a major disability so that they are fully prepared to accept all the risks of arthroplasty in an attempt to regain a worthwhile arc of movement. Thus the only situation in which I might contemplate undertaking an elbow arthrodesis would be in the case of an intolerably painful or unstable joint in a young man requiring to undertake heavy manual work.

\section{TOTAL JOINT REPLACEMENT}

Although there had been sporadic reports of hinged arthroplasty of the elbow over the previous 30 years, this technique did not really become established until the era of methylmethacrylate fixation. This development was pioneered in the United Kingdom in the late 1960 s and early 1970s when several hinged designs became available-namely, the McKee, the Shiers, and the Dee implants. The early results of these procedures were often extremely successful, pain relief being excellent as was recovery of movement. ${ }^{19}$ All too soon, however, dire problems began to make their appearance in the form of loosening of the implant, especially in the humerus, with most alarming thinning and ballooning of the distal humeral shaft (fig 10), which rendered the patient liable to an extremely severe comminuted fracture in the event of a fall..$^{20-22}$ Moreover, if the prosthesis had to be removed because of infection 


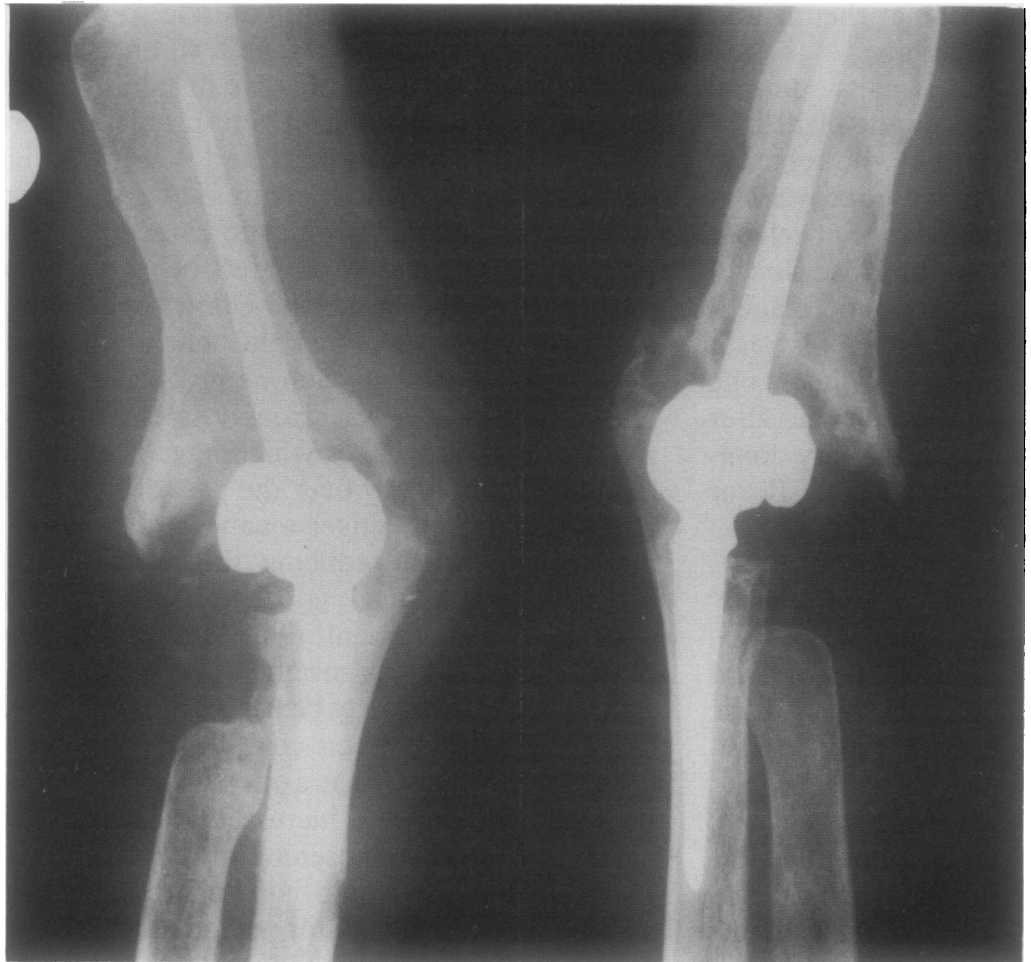

Figure 10 Radiographs of bilateral hinge arthroplasties of the elbow. These films taken five years after surgery show the gross loosening that was so common with this type of fully constrained replacement. Note the thinning and ballooning of the distal humeral cortex.
The third problem is the cyclical reversal of the resultant vector of the forces across the elbow. With the elbow in extension this force is directed anteriorly, whereas in flexion the force is directed posteriorly.

Four possible solutions might be tried: $(a)$ the use of much more extensive fixation; $(b)$ a narrow hinge allowing retention of the collateral ligaments; $(c)$ a partially constrained hinge; $(d)$ a two component joint. All these methods are being pursued in various parts of the world and it is possible to classify the currently available elbow prostheses into various groups according to their articular mechanism and method of humeral fixation. ${ }^{23}$

\section{Linked prostheses}

Group 1-Fully constrained hinges with supplemented stem fixation-for example, the Nederpelt prosthesis.

Group 2-Slim hinges fitting between the condyles of the humerus so that ligamentous support can be retained-for example, the Stanmore $^{24}$ and St Georg prostheses.

Group 3-Partially constrained or 'floppy hinges'-for example, triaxial prosthesis. ${ }^{25}$

Group 4-Semiconstrained hinges using intramedullary and condylar fixation-for example, the latest model of the GSB prosthesis ${ }^{26}$ and the more recent Mayo modification of the Coonrad II implant. ${ }^{27}$

the patient was left with a highly unstable pseudarthrosis. Because of these problems elbow arthroplasty in the mid-1970s acquired an unenviable reputation from which it has not yet recovered in the minds of many orthopaedic surgeons.

Three main causes can be cited for these disastrous results. First and foremost come the rotational stresses, which are transmitted to the cement/bone interface in the humerus during activities such as lifting an object between the palms of the hands. In order to do this an internal rotation force must be generated on the humerus and then transmitted across the elbow. In the normal elbow there is a wide bone surface for this transmission and any tendency for the elbow to buckle outwards is resisted by the tiebeam of the medial collateral ligament. In the original hinges, however, where the condyles were removed and with them the proximal ligamentous attachments the only mechanism for transmitting the rotational force from arm to forearm was through the cement/bone interface in the humerus, the latter acting as a box spanner on the stem of the implant. Moreover, it was just at this point that the maximum loosening problem was observed.

The second important factor is the posterior pull of such muscles as the brachioradialis with the elbow at $90^{\circ}$. Certainly once any minor loosening has been established, the pull of such forces will tend to push the hilt of the prosthesis backwards while angling the tip of the stem forwards against the anterior cortex of the humerus, and indeed ballooning and eventual perforation of the anterior cortex was only too commonly observed.

\section{Unlinked prostheses}

Group 5-Shell fit surface replacements-for example, Lowe/Miller, Kudo I, Roper-Tuke, ${ }^{28}$ Millar-Amis, and Sorbie prostheses.

Group 6-Shell fit surface replacements with added fixation by intramedullary stems-for example, Ewald (capitellocondylar ${ }^{29} 30$ ) and Kudo III prostheses.

Group 7-Unlinked stemmed prostheses with a solid trochlea-for example, Wadsworth II, Imura, and Stiles (Guildford) prostheses.

Group 8-Similar to group 7 but with added condylar fixation from projecting flanges or shell-like extensions from the articular surface-for example, the Norwegian prosthesis and the long stemmed version of the SouterStrathclyde prosthesis.

Group 9-Solid trochlear replacement with very short condylar flange fixation-Cavendish-Elloy (Liverpool prosthesis ${ }^{31}$ ).

Group 10 -Solid trochlear replacement with condylar flange fixation supplemented by metal stirrup in supracondylar ridges - Souter-Strathclyde prosthesis. ${ }^{32}$

All the above approaches have met with some degree of success so that the results of elbow arthroplasty are now much better than those using the original hinges.

\section{Clinical results}

My own experience, of about 275 operations carried out since 1977, has been with the Souter-Strathclyde prosthesis (figs 11 and 12). Between 1977 and 1983112 elbows of 94 


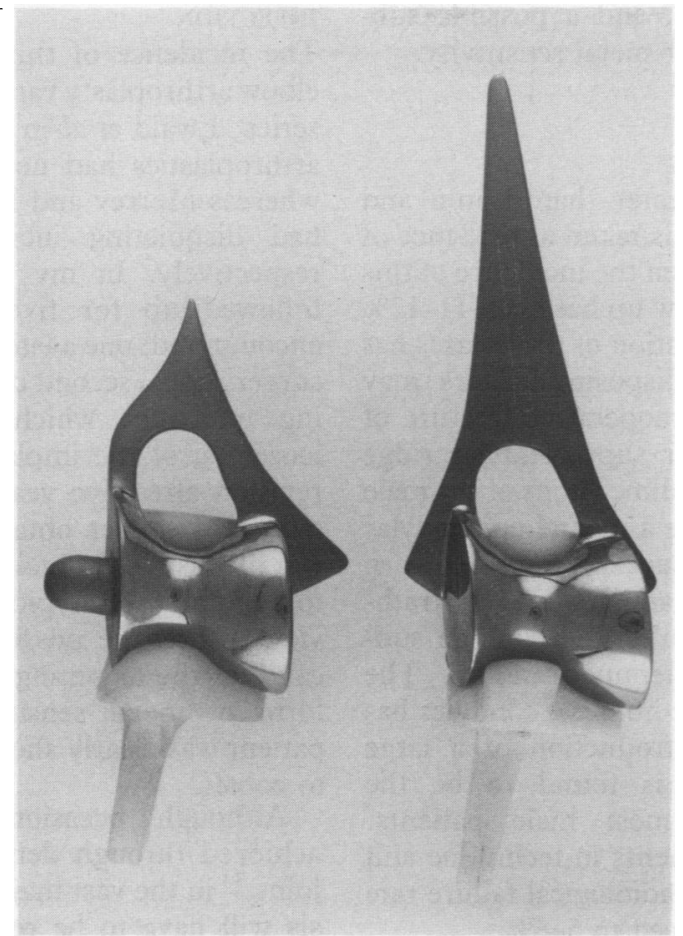
standard model is shown on the left, and is available in three sizes of humeral component and two sizes of ulnar. The long stemmed model on the right is for use in cases of very severe humeral erosion. All humeral components are fully compatible with either of the ulnar sizes.

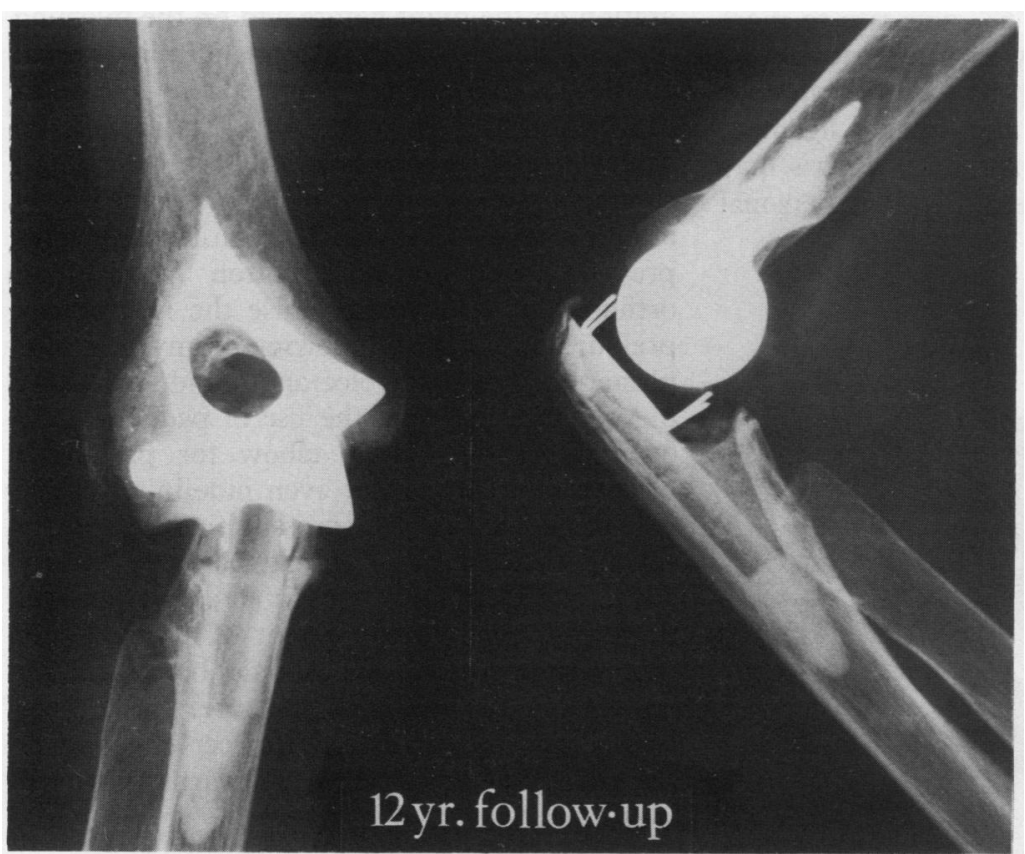

Figure 12 Radiographs of Souter-Strathclyde prosthesis in situ with no evidence of loosening 12 years after surgery.
Figure 11 Souter-Strathclyde elbow prosthesis. The

free from pain or subject to only occasional twinges at one year after surgery. This figure is well maintained at five years after surgery.

The recovery of flexion has also proved very acceptable: the mean flexion before surgery was $127^{\circ}$ and at one year after surgery $143^{\circ}$. Once more this has been well maintained at the five year follow up. What is particularly encouraging is that if one starts with minimal loss of flexion but a very painful joint there is very little risk of losing flexion, while if one starts with major limitation of flexion there is an excellent chance of gaining very worthwhile improvement.

The gains in supination and pronation have also been very acceptable.

Improvement of extension, however, is much less satisfactory, the mean figure being identical before and after surgery. It seems that if one starts with a minimal flexion deformity before surgery one may actually lose some of the extension range. With a flexion deformity in the midrange, movement is likely to remain very much the same, and only if there is a very severe preoperative deformity is there likely to be an appreciable gain. Fortunately, the presence of a moderate flexion deformity seems to be less disturbing to the patient than to the surgeon.

\section{Complications}

Even with the newer techniques total replacement of the elbow has been beset by a surprisingly high number of complications. Fortunately most of these are quite mild and transitory, while many of the others, though potentially serious, can be aborted very successfully provided they are recognised early and dealt with appropriately by an experienced team. If, on the other hand, they are neglected, what at first may seem to be a minor problem can rapidly escalate into a total catastrophe. Accordingly, although elbow arthroplasty can now be regarded as a well established and reliable part of the surgeon's armamentarium, it is important that it continues to be done in units with a sufficient number of rheumatoid patients to ensure that the surgeon and his supporting paramedical team can acquire the necessary experience and skill for the successful management of these cases.

In my own series of 112 cases followed up for over five years $71 \%$ had no complications at all. A further $6 \%$ had minor complications such as ulnar or radial nerve palsy, which have resolved completely without further surgical intervention. Another $6 \%$ had transient complications, such as severe ulnar nerve palsy, necrosis of wound margins, fracture of the medial epicondyle, or temporary instability, which were dealt with very satisfactorily by further minor surgical interventions not entailing revision of either joint component. Thus the series as a whole eventually achieved an $83 \%$ success rate. plasty. Twenty of these patients died and four were lost to follow up. Seventy remain under review so that five year follow up data are available on 85 elbows.

The pain relief experienced by these patients has been extremely gratifying. Whereas before surgery 82 of the 85 elbows were the seat of very significant pain, 78 of the elbows were either

\section{CLINICAL LOOSENING}

Only four clinical loosenings have occurred and these have all been secondary to specific problems-namely, a fracture of the medial epicondyle, a fracture of the olecranon, per- 
manent total dislocation, and a possible subacute chronic infection or metal sensitivity.

\section{RADIOLOGICAL LOOSENING}

If a radiolucent line greater than $1 \mathrm{~mm}$ and showing signs of activity is taken as evidence of radiological loosening, then the incidence of this problem at five year follow up has been 11-12\% (fig 13). Further investigation of these cases has suggested that two predisposing factors may operate-namely, an intraoperative fracture of the medial epicondyle or supracondylar ridge and, secondly, the larger dimensions of the male humeral condyles. Where a medial epicondylar fracture does occur at surgery I would warn against the use of the standard Souter-Strathclyde prosthesis and would advocate the substitution of the long stemmed model. The problem of the large male humeral condyles has been assisted by the introduction of a large humeral model, which is found to be the appropriate choice in most male patients. Through these improvements in technique and design we hope that the radiological failure rate at five years will be reduced to $5-6 \%$.

\section{ULNAR NERVE PALSY}

In most series of elbow arthroplasties currently reported there has been a considerable incidence of ulnar nerve palsy. In my own series the incidence was $14 \%$. Fortunately, most of these have resolved, but about $6 \%$ give rise to more persistent trouble and may require treatment by anterior transposition. There is some evidence that a routine release of the arcuate ligament spanning the heads of flexor carpi ulnaris may greatly alleviate this problem (Beddow, personal communication).

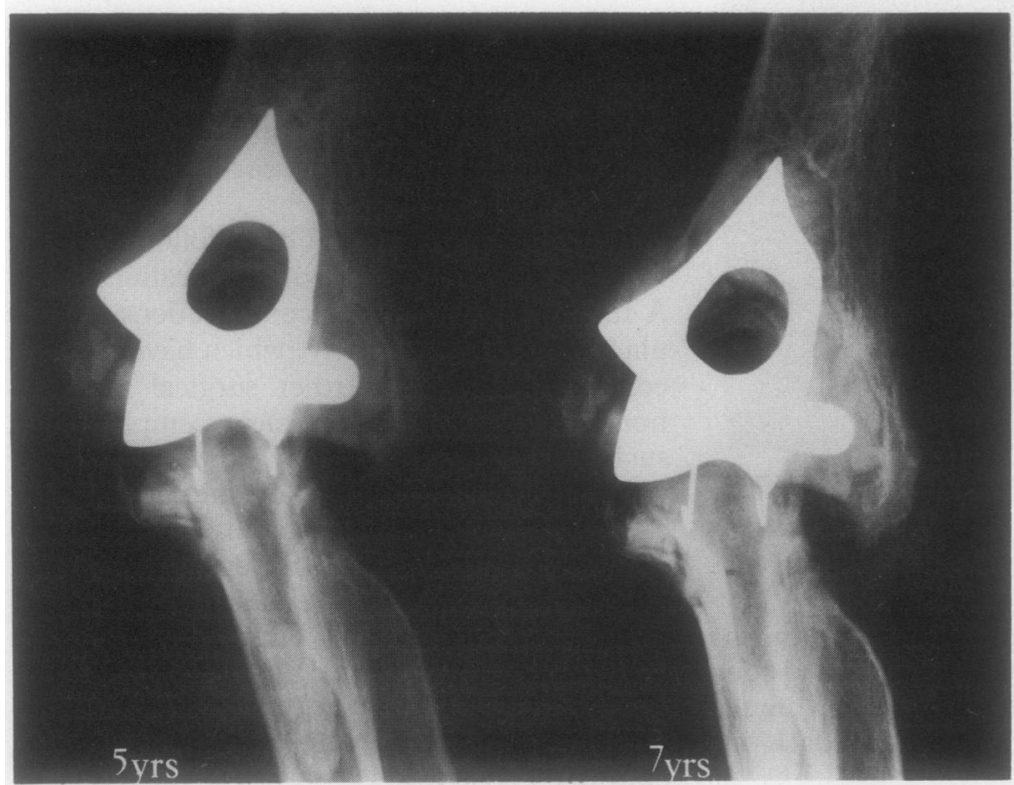

Figure 13 Radiographs showing evidence of radiological loosening at five and seven years after surgery. Clinically the elbow remains entirely free from symptoms with unimpaired function. Note that the appearances have progressed only very slowly and so far there has been no sign of the extreme thinning and ballooning of the surrounding bone that was such an alarming problem with the early fully constrained hinge replacements.

\section{INFECTION}

The incidence of this ultimate catastrophe of elbow arthroplasty varies very widely in different series. Ewald et al in their original series of 69 arthroplasties had no deep infections at all, ${ }^{29}$ whereas Morrey and Bryan ${ }^{33}$ and Roper et al ${ }^{28}$ had disquieting incidences of 9 and $10 \%$ respectively. In my own series of 112 cases followed up for five years two cases were encountered: one a late infection four years after surgery and a second case of subacute smouldering infection, which eventually resulted in loosening of the implant and the necessity for revision after five years. No positive bacterial culture was ever obtained from this case, nor was the histology obtained at revision considered to be in any way typical of an infected joint. In view of this the possibility does exist that the cause of the loosening in this patient was some form of metal sensitivity, especially as the patient was clearly shown to be highly sensitive to cobalt.

Although occasional resolution may be achieved through debridement of the affected joint, ${ }^{33}$ in the vast majority of cases the prosthesis will have to be removed. Fortunately, the resulting pseudarthrosis, perhaps because of the scarring which follows the acute infection, may provide a remarkably functional joint.

In view of the disastrous consequences of this complication every possible precaution must be taken to prevent its occurrence. My own preoperative regimen includes careful skin preparation on the night before and on the morning of surgery, the use of systemic antibiotics and antibiotic impregnated cement, the release of the tourniquet so that haemostasis can be achieved before closure, the use of closed suction drainage, the application immediately after surgery of a massive multilayered compression bandage using cotton rather than orthopaedic wool to minimise the risk of any pressure sores, the windowing of any posterior plaster shell over the olecranon, and, especially in very thin patients, the use of padded muffs over the point of the elbow for prolonged periods after surgery or even indefinitely. The risk of development of pressure sores over the tip of the olecranon must be very clearly appreciated. Moreover, such sores may be full thickness, even to the extent of affecting the triceps aponeurosis, and should be treated by immediate excision with resuture. If they are left to separate secondarily, direct infection of the prosthesis from without-inwards is almost inevitable.

\section{INSTABILITY}

One of the chief concerns in the minds of many surgeons is the possible instability of surface or unlinked elbow replacements. These doubts seem to arise from a misconception that the collateral ligaments of the elbow are destroyed by rheumatoid disease. This in fact is not the case. During the exposure for an elbow arthroplasty the annular ligament should be carefully divided so that at the end of the operation it is available for reattachment under the tension appropriate to the situation existing after the 
excision of the head of the radius. After this repair very sound posterolateral stability will be restored as the posterior band of the collateral ligament sweeps down and becomes merged as one with the annular ligament. Although it is necessary to sacrifice the posterior fibres of the medial collateral ligament during exposure, the anterior band of the medial collateral ligament, which is perhaps the most important single stabilising soft tissue structure in the elbow, must be carefully preserved. Just as in knee surgery it has come to be realised that with the new surface replacements the management of the soft tissues is of vital importance, so does this apply to surface replacements of the elbow. With careful attention to these details the incidence of postoperative instability in my own series has been only $3 \cdot 5 \%$. The usual cause of instability resulting in a lateral subluxation or dislocation is a disruption of the medial suture line. Such cases should be taken back to theatre so that the suture line can be repaired and, if necessary, reinforced by fashioning an accessory medial ligament from the deep fascia over the flexor origin. After this secondary intervention there is every reason to expect that the patient will go on to a perfectly satisfactory and stable result.

Only very rarely should the problem of instability be found to be intractable. If this does occur, complete revision to a fully linked prosthesis can provide a solution.

\section{More unusual situations for surgical management} JUVENILE CHRONIC ARTHRITIS

Although it would only be with the greatest reluctance that one would advocate total joint replacement in a teenager or very young adult, circumstances do occur when this line of treatment should perhaps be considered. It is a curious fact that in juvenile chronic arthritis the elbow will commonly ankylose in relative extension. If this occurs bilaterally, with complete bony ankylosis in elbow, radioulnar, and wrist joints, and with the elbow in an extended position of sometimes as much as $20^{\circ}$, the disability for the patient can be appalling so that total replacement arthroplasty of the elbow, at least on one side, is fully justifiable. Moreover, the restoration of movement in such cases can be very gratifying.

\section{THE FLAIL ELBOW}

It must be realised that there are limitations to the use of an unlinked elbow prosthesis. In the most severe forms of rheumatoid destruction, where the elbow has become essentially flail and ligamentous continuity has been lost, recourse must be made to a linked prosthesis. A modified form of my own implant has been developed for such cases (fig 14). In this the ulnar component is supported in a metal carriage with a $5 \mathrm{~cm}$ intramedullary stem while the high density polyethylene trochlear notch is fashioned to a contour slightly greater than a semicircle so that a snapfit over the waist of the metal trochlea becomes possible, the prosthesis thus having

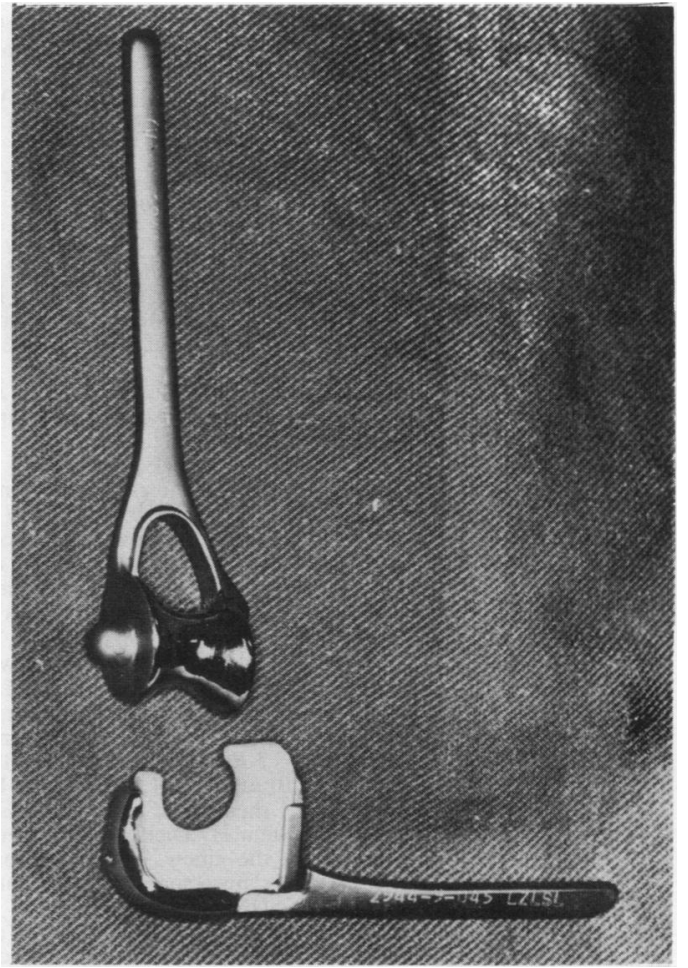

Figure 14 Example of a custom built snapfit modification of the Souter-Strathclyde prosthesis, for use in elbows in which ligamentous stability has been lost.

inherent stability. Such implants should be only rarely required in primary rheumatoid surgery, but will be fairly commonly necessary in revision surgery.

\section{Summary and conclusions}

I suggest that for too long the problem of the rheumatoid elbow, particularly the need for surgical intervention, has been underestimated. Where the latter has been advocated the philosophy has been adopted that synovectomy and debridement with excision of the head of the radius is probably all that is required, or that in the late case excision arthroplasty may yield an adequate result. I suggest that these approaches are no longer tenable. Synovectomy and debridement with or without excision of the head of the radius does indeed retain an extremely valuable place in the management of stage 1,2 , and early stage 3 disease. In the later stages of the disease, however, serious consideration must now be given to total joint replacement, the results of which can be remarkably successful and durable, and the complications from which can now be contained within acceptable limits provided that the operating team is fully experienced. It must also be stressed how necessary it is in the medical or combined clinic to pursue careful clinical and radiological monitoring of the rheumatoid elbow so that signs of dangerous deterioration can be recognised early, and surgery applied at a time when optimal conditions for the particular surgical weapons to be used still exist.

1 Laine V, Vainio K. Synovectomy of the elbow. In: Hijmans W, Paul W D, Herschel H, eds. Early synovectomy in rheumatoid arthritis. Amsterdam: Excerpta Medica, 1969 117-8. 
2 Freyberg R H. A study of the time of onset of structural joint damage in rheumatoid arthritis. Arthritis Rheum 1968; 11: 481 .

3 Porter B B, Richardson C, Vainio K. Rheumatoid arthritis of the elbow: the results of synovectomy. F Bone foint Surg $[B r]$ 1974; 56: 427-37.

4 Gschwend N. Surgical treatment of rheumatoid arthritis. Philadelphia: Saunders, 1980.

5 Hastings D E, Kwok J. Rheumatoid elbow deformity [Abstract]. F Bone foint Surg [Br] 1982; 64: 634.

6 Nicol A C, Berme N, Paul J P. A biomechanical analysis of elbow joint function. In: foint replacement in the upper limb. elbow joint function. In: Foint replacement in the upper limb. London: Mechanical Engineers Publications, 1977: 45-51.
(Institute of Mechanical Engineers conference publications, (Institute

7 Wilson D W, Arden G P, Ansell B M. Synovectomy of the elbow in rheumatoid arthritis. F Bone Foint Surg [Br] 1973; 55: $106-11$

8 Morrey B F, Askew L J, An K N, Chao E Y. A biomechanical study of normal functional elbow motion. f Bone foint Surg [Am] 1981; 63: 872-6.

9 Mori M. Surgical experience of synovectomy in the rheumatoid elbow. In: Delchef J, ed. Onzieme Congress International de Chinurgie Orthopedique et de Traumatologie. Brussels: Bruxelles Imprimerie des Sciences SA, 1970: 140.

10 Inglis A E, Ranawat C S, Straub L R. Synovectomy and debridement of the elbow in rheumatoid arthritis. $\mathcal{F}$ Bone foint Surg [Am] 1971; 53: 652-62.

11 Marmor L. Surgery of the rheumatoid elbow. Follow-up study on synovectomy combined with radial head excision. f Bone foint Surg [Am] 1972; 54: 573-8.

12 Brattstrom H, Alkhudairy H. Synovectomy of the elbow in rheumatoid arthritis. Acta Orthop Scand 1975; 46: 744-50.

13 Stein H, Dickson R A, Bentley G Rheumatoid arthritis of the elbow. Pattern of joint involvement, and results of synovectomy with excision of the radial head. Ann Rheum Dis 1975; 34: 403-8.

14 Summers G D, Webley W, Taylor A R. Synovectomy and excision of the radial head in rheumatoid arthritis: a short term palliative procedure [Abstract]. Clinical and Experiterm palliative procedure [Abstract]. Clinical and Experimental Rheumatology 1987; 5 (suppl 2): 115. (XIth European
Congress of Rheumatology, European League Against Congress of Rheumato

5 Souter W A. Le traitement chirurgical du coude rhumatoid. Cahiers d'enseignement de la SOFCOT conferences d'enseignment 1987. Paris: Expansion Scientifique Française, 1987 159-72

16 Marmor L, Lawrence J F, Dubois E L. Posterior interosseous nerve palsy due to rheumatoid arthritis. $\mathcal{f}$ Bone foint Surg [Am] 1967; 49: 381-3.
17 Millender L H, Nalebuff E A, Holdsworth D E. Posterior

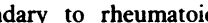
arthritis. F Bone foint Surg [Am] 1973; 55: 753-7.

18 Hurri L, Pulkki T, Vainio K. Arthroplasty of the elbow in rheumatoid arthritis. Acta Chir Scand 1964; 127; 459-65.

19 Souter W A. Arthroplasty of the elbow with particular reference to metallic hinge arthroplasty in rheumatoid patients. Orthop Clin North Am 1973; 4: 395-413.

20 Souter W A. Metallic hinge arthroplasty in the rheumatoid elbow [Abstract]. F Bone foint Surg [Br] 1973; 55: 874 .

21 Dee R. Five years' experience with total replacement of the elbow. In: Joint replacement in the upper limb. London: elbow. In: Foint replacement in the upper $\operatorname{limb}$. London: of Mechanical Engineers conference publications, No 5.)

22 Souter W A. Total replacement arthroplasty of the elbow. In foint replacement in the upper limb. London: Mechanical Engineers Publications, 1977: 99-106. (Institute of Mechanical Engineers conference publications, No 5.)

23 Souter W A. Total replacement arthroplasty of the elbow. In Wadsworth T G, ed. The elbow. 2nd ed London and Edinburgh: Churchill Livingstone (in press).

24 Johnson J R, Getty C J M, Lettin A W F, Glasgow M M S. The Stanmore total elbow replacement for rheumatoid arthritis. F Bone Foint Surg [Br] 1984; 66: 732-6.

25 Inglis A E, Pellici P M. Total elbow replacement. 7 Bone foint Surg [Am] 1980; 62: 1252-8.

26 Steiger J U, Gschwend N, Bell S. GSB elbow arthroplasty: a new concept and six years' experience. In: Kashiwagi D ed. Elbow joint, Proceedings of the International Seminar, Kobe, Fapan. Amsterdam: Excerpta Medica, 1985: 285-93. (Excerpta Medica International Congress Series No 678.)

27 Morrey B F, Bryan R S. Total joint replacement. In: Morrey $\mathrm{B} F$, ed. The elbow and its disorders. Philadelphia: Saunders, 1985: 546-69.

28 Roper B A, Tuke M, O'Riordan S M, Bulstrode C J. A new unconstrained elbow. A prospective review of 60 replacements. F Bone foint Surg [Br] 1986; 68: 566-9.

29 Ewald F C, Scheinberg R D, Poss R, et al. Capitello condyla total elbow arthroplasty. Two to five year follow-up in rheumatoid arthritis. F Bone foint Surg [Am] 1980; 62: 1259-63.

30 Ewald F C, Jacobs M A. Total elbow arthroplasty. Clin Orthop 1984; 182: 132-42.

31 Soni R K, Cavendish M E. A review of the Liverpool elbow prosthesis from 1974 to 1982 . F Bone foint Surg [Br] 1984 66: 248-53.

32 Souter W A. A new approach to elbow arthroplasty. Eng Med 1981; 10: 59-64.

33 Morrey B F, Bryan R S. Infection after total elbow replacement. F Bone Foint Surg [Am] 1983; 65: 330-8. 